\title{
Characterization of sugar diversity in floral and extra-floral nectar from the Coastal Coral Tree (Erythrina caffra Thunb.) in Southern California
}

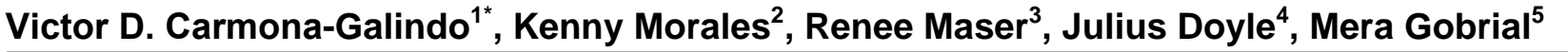 \\ ${ }^{1}$ Biology Department, Loyola Marymount University, Los Angeles, USA; *Corresponding Author: vcarmona@lmu.edu \\ ${ }^{2}$ Global Health Sciences Program, University of California at San Francisco, San Francisco, USA \\ ${ }^{3}$ Environmental Science Program, Loyola Marymount University, Los Angeles, USA \\ ${ }^{4}$ Department of Anthropology, University of Washington, Seattle, Washington DC, USA \\ ${ }^{5}$ Global Medicine Program, University of Southern California, Los Angeles, USA
}

Received 26 September 2013; revised 26 October 2013; accepted 2 November 2013

Copyright (C) 2014 Victor D. Carmona-Galindo et al. This is an open access article distributed under the Creative Commons Attribution License, which permits unrestricted use, distribution, and reproduction in any medium, provided the original work is properly cited. In accordance of the Creative Commons Attribution License all Copyrights (C) 2014 are reserved for SCIRP and the owner of the intellectual property Victor D. Carmona-Galindo et al. All Copyright (C) 2014 are guarded by law and by SCIRP as a guardian.

\section{ABSTRACT}

The Coastal Coral Tree (Erythrina caffra Thunb.) produces floral nectar (FN) that serves to attract pollinating insects, but also secretes nectar from extra-floral (EFN) glands that serves to attract predatory insects, such as ants. While studies on myrmecophytes (i.e. specialized plants that attract and interact with ants) have primarily focused on interspecific evaluations of EFN chemistry, the Coastal Coral tree offers an opportunity to contrast intraspecific nectar chemistry with differing evolutionary and ecological functions. We hypothesized that the richness of (molecular) sugar species, relative concentrations, and diversity of sugars in FN and foliar EFN would diverge due to differences in the ecological role of the two types of nectar. High performance liquid chromatography with refractive index detection was used to identify the richness of sugar species (based on retention time), measure the relative concentrations, and evaluate the diversity of sugars in FN and foliar EFN secretions. We detected sugar species unique to each gland type and reported significant differences in the relative concentration of one sugar species common to both gland types. While the mean diversity index of sugars was similar for both gland types, the diversity of foliar EFN sugars was significantly more variable than that of FN sugars. The composition of FN showed little variation, and was reflective of its fundamental role in plant reproduction. Foliar
EFN, however, demonstrated the variability expected of a context-dependent myrmecophyte that interacts with a facultative ant species assemblage across a mosaic of abiotic and biotic conditions.

\section{KEYWORDS}

Chemical Ecology; Diversity Index; Exotic Species biology; Myrmecophyte; Nectar Chemistry

\section{INTRODUCTION}

Myrmecophytic plants attract predatory insects, such as ants [1], wasps and parasitoids [2], to form mutually beneficial relationships [3]. The predatory insects provide myrmecophytes with services such as seed dispersal [4], gathering of nutrients [5], or defense against herbivores [6]. In return, myrmecophytes provide rewards such as extra-floral nectar [7], proteinaceous food bodies [8], and shelter in the form of domatia [9].

In Southern California, the Coastal Coral tree (Erythrina caffra Thunb.) is an exotic myrmecophyte that is native to coastal forests of the Eastern Cape region of South Africa [10]. The Coastal Coral tree produces abundant floral nectar $(\mathrm{FN})$ between the months of winter and early spring [11] and extra-floral nectar (EFN) from calyxine and foliar glands [12]. While the role of FN in Erythrina is to attract pollinators [13,14], the role of EFN glands in myrmecophytes is an active area of research [15]. 
The literature advances four hypotheses that address the evolutionary role of EFN in myrmecophytes: 1) EFN glands serve as a waste excretion site for the plant, where excess fluids can be eliminated [16,17]; 2) EFN serves as a biotic defense mechanism for myrmecophytes, which attract predatory insects, such as ants, that in turn protect the plant tissues from herbivores [6]; 3) EFN deters ants from tending trophobionts, which feed on plant phloem and secrete honeydew as a reward for ant-provided defense [18]; 4) EFN serves to distract ants from visiting flowers $[19,20]$.

While many studies of myrmecophytes have focused on interspecific surveys of EFN chemical constituents [21], the Costal Coral tree offers an opportunity to conduct intraspecific contrasts of FN and EFN sugar composition. The objective of this study was to use High Performance Liquid Chromatography with Refractive Index Detection (HPLC-RID) to evaluate the retentive identity (i.e. species) and concentration of sugars secreted by both FN and foliar EFN glands on Coastal Coral trees in Southern California. We hypothesized that the richness, relative concentration, and diversity of sugars in FN and foliar EFN would diverge due to differences in the ecological role of the glands.

\section{MATERIALS AND METHODS}

\subsection{Field Sampling}

The FN and foliar EFN samples were collected on 8 12 April 2013 between 800 - 1100 hrs from five Coral trees located on Loyola Marymount University, Los Angeles CA. The trees were selected based on height (10 $15 \mathrm{~m}$ tall), and growing in a high light environment (i.e. no canopy overlap). A given FN sample was extracted from multiple flowers on a single inflorescence, and stored in a $1.5 \mathrm{ml}$ micro-centrifuge tube. A given foliar EFN sample was collected from the EFN glands on 10 15 young expanding leaves from each Coastal Coral tree. The two standard paper-punch sized discs of Whatman chromatography paper were used to dab foliar EFN glands until saturated, and stored in $1.5 \mathrm{ml}$ micro-centrifuge tubes.

\subsection{Lab Preparation}

To prepare the FN samples, two clean chromatography disc papers were submerged into the micro-centrifuge tubes with the FN that was collected in the field and then resuspended in $0.5 \mathrm{ml}$ of MilliQ water. To prepare the foliar EFN samples, the two original discs collected in the field were resuspended in $0.5 \mathrm{ml}$ of MilliQ water. Both the FN and foliar EFN solutions were vortexed for 3 min, and filtered using a 1.2 nylon pore Cameo 25 NS filter.

\subsection{HPLC Methodology}

Aliquots of $10 \mu \mathrm{l}$ of diluted FN and foliar EFN were injected into a Waters HPLC system outfitted to a Waters 2414 Refractive Index Detector and a Carbohydrate Analysis Column (WAT084038). The HPLC-RID operated with a mobile phase of $85 \%$ acetonitrile, flow rate of $3 \mathrm{ml} / \mathrm{min}$, column temperature of $50^{\circ} \mathrm{C}$, detector temperature of $50^{\circ} \mathrm{C}$, and pressure of approximately 1000 psi. Two runs were conducted for a given nectar sample to ensure consistency of chromatograms, however only one of the runs was integrated to avoid pseudoreplication. Peak integration was conducted with an area method of quantitation using Empower 2 (version 2008).

\subsection{Data Analysis}

In a chromatogram, sugar species were identified by the retention time (RT) of a given peak. The relative abundance of a sugar species was determined by using the area under a peak. The peak area $\left(\mu v^{*} s\right)$ for a given sugar species was reported as a percent (\%) of the total peak area $\left(\mu v^{*} s\right)$ for all of the sugar species in the chromatogram. The richness and relative abundance of sugar species were evaluated for unique and shared sugar species between FN and foliar EFN samples. We evaluated the distribution of the relative abundance of sugar species shared between FN and foliar EFN using a ShapiroWilks test for normality. We compared the mean abundance of shared sugar species between FN and foliar EFN using a Mann-Whitney U test. We used the sugar species richness and relative abundance to calculate a Shannon-Weiner diversity index $(\mathrm{H})$ using Equation (1):

$$
H=-1 \sum p_{i} * \ln p_{i}
$$

where $p_{i}$ is the proportional abundance of the $i^{\text {th }}$ species relative to the total abundance of all sugar species [22]. We evaluated the distribution of sugar diversity indices of FN and foliar EFN using a Shapiro-Wilks test for normality. We compared the mean diversity index of sugars detected in FN and foliar EFN using a MannWhitney U test. We compared differences in the variance of sugar diversity indices between FN and EFN using an F-test.

\section{RESULTS}

There was a total of four sugar species detected between FN and foliar EFN (Figure 1). One sugar species (RT 1.7 min) was unique to FN, two sugar species (RT $1.9 \mathrm{~min}$ and RT $2.6 \mathrm{~min}$ ) were unique to foliar EFN, and one sugar species (RT $1.8 \mathrm{~min}$ ) was common to both FN and foliar EFN. The peak area for the sugar species RT 1.8 min was not normally distributed $(\mathrm{W}=0.8221, \mathrm{P}<$ $0.05)$. The mean peak area (\%) of sugar species RT 1.8min was significantly greater in FN than foliar EFN 


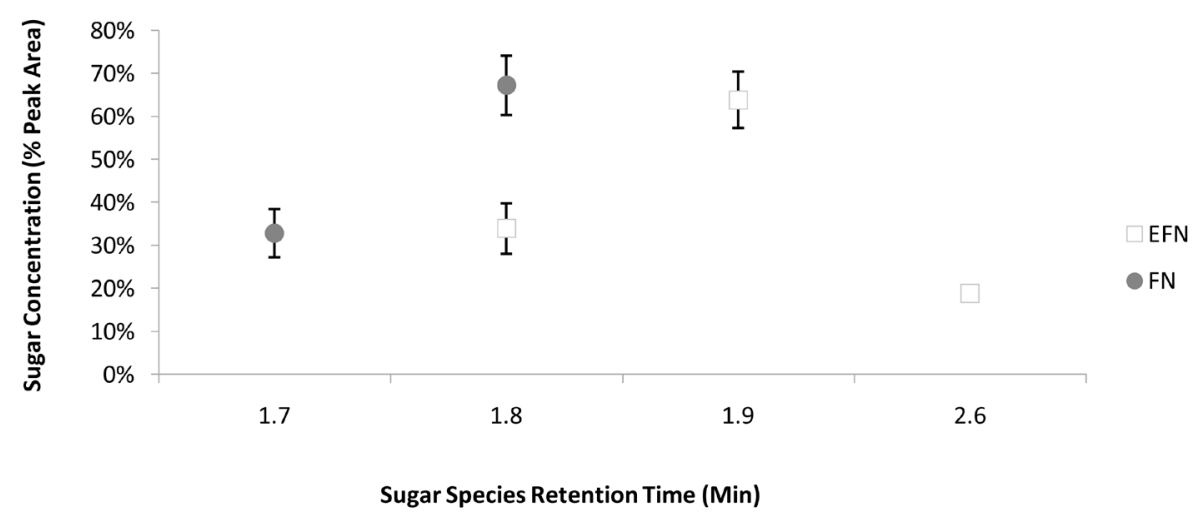

Figure 1. The retentive species and relative concentration of sugars detected in FN and EFN secretions. Bars denote 95\% Confidence Intervals.

$(\mathrm{U}=0.01, \mathrm{P}=0.0122$, Figure 2). Sugar diversity index values were not normally distributed $(\mathrm{W}=0.5318, \mathrm{P}<$ $0.05)$. The mean sugar diversity index values of FN did not differ significantly from foliar EFN values ( $\mathrm{U}=9.0$, P $=0.5309$, Figure 3). However, the variance of FN sugar diversity index values was significantly lower than foliar EFN values $(F=0.0369, P=0.0037$, Figure 3$)$.

\section{DISCUSSION}

The HPLC-RID methodology detected a total of four distinct sugar species; one unique to FN (RT $1.7 \mathrm{~min}$ ), two unique for EFN (RT 1.9 min and RT $2.6 \mathrm{~min}$ ), and one common to both FN and EFN secretions (RT 1.8 min). The sugar species common to both gland types (RT $1.8 \mathrm{~min}$ ) was detected in significantly greater concentrations in FN than foliar EFN secretions. While the mean diversity of the sugars secreted did not change between both gland types, the diversity values of foliar EFN sugars were significantly more variable than those of FN sugars.

The intraspecific contrasts of FN and foliar EFN secreted by the Coastal Coral tree revealed that the variability in sugar composition reflected ecological differences in the role of the respective nectar-secreting gland [23,24]. The conserved variance of FN sugar diversity can be attributed to its role in attracting bird and insect pollinators [25], wherein increased variation would negatively impact plant fitness. The greater variance of sugar diversity detected in foliar EFN is expected for a myrmecophytic species that can interact facultatively with a plethora of ant species inside and outside of its native range [26].

Given that the Costal Coral tree is an exotic species, the variability in the diversity of foliar EFN sugars may also reflect conditionality in the cost/ benefit outcome of a facultative mutualism in a non-native abiotic and biotic environment [27-29]. In southern California, reproductively mature Costal Coral trees are found in managed urban habitats, experience low levels of herbivory, and

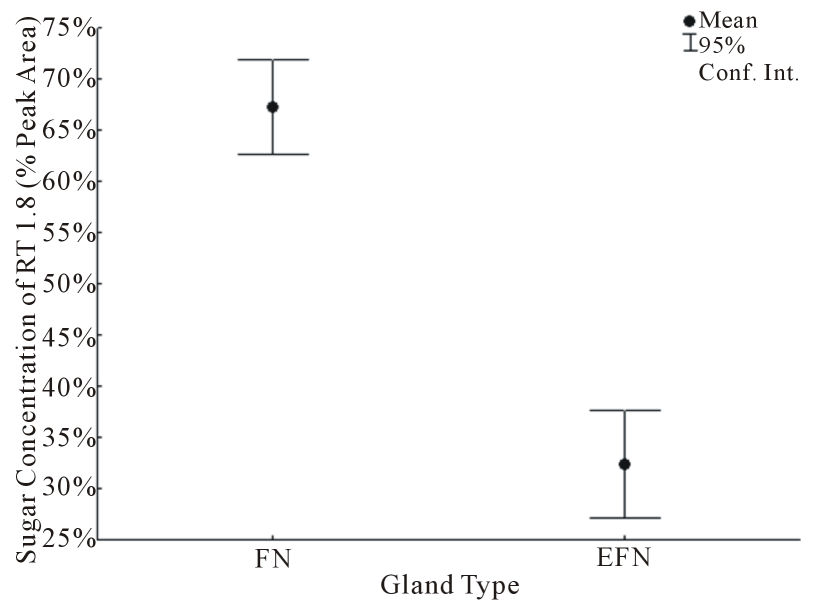

Figure 2. The relative concentration of sugar species RT 1.8 min in both FN and EFN secretions.

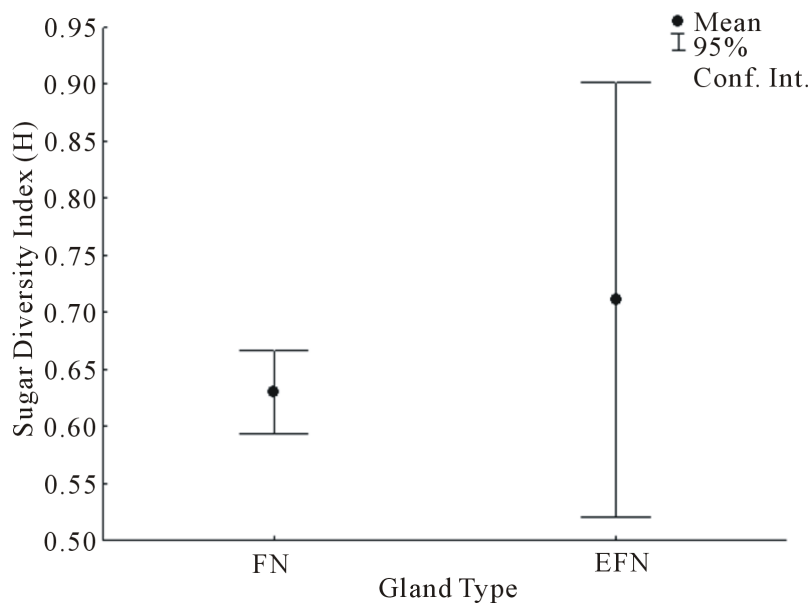

Figure 3. The diversity index values of sugars detected in FN and EFN secretions.

ants are rarely observed visiting foliar EFN glands (pers. obs.). As such, future intraspecific contrasts of EFN gland secretions from exotic Costal Coral trees may expect that the sugar composition from calyxine EFN 
glands more closely resemble the variability and diversity from foliar EFN glands rather than the conservative FN glands.

\section{ACKNOWLEDGEMENTS}

We would like to thank L.G. Carmona Solano for his valuable help with Refractive Index Detection, as well as G. Kuleck and L. Towner for their help coordinating hardware improvements for the Waters HPLC system. This project was supported by a Kadner-Pitts Research Grant from the Loyola Marymount University (LMU) Biology Department and a Continuing Faculty Grant from the LMU Frank R. Seaver College of Science \& Engineering. Student support was funded by a grant from the Beta Beta Beta National Biological Honor Society, as well as through stipends from both the LMU Undergraduate Research Opportunities Program and the LMU Summer Undergraduate Research Program.

\section{REFERENCES}

[1] Hölldobler, B. and Wilson, E.O. (1990) The ants. Belknap Press of Harvard University Press, Cambridge.

[2] Cuautle, M. and Rico-Gray, V. (2003) The effect of wasps and ants on the reproductive success of the extrafloral nectaried plant Turnera ulmifolia (Turneraceae). Functional Ecology, 17, 417-423. http://dx.doi.org/10.1046/j.1365-2435.2003.00732.x

[3] Beattie, A.J. (1985) The evolutionary ecology of ant-plant mutualisms. Cambridge University Press, Cambridge.

[4] Ness, J.H., Bronstein, J.L., Andersen, A.N. and Holland, J.N. (2004) Ant body size predicts dispersal distance of ant-adapted seeds: Implications of small-ant invasions. Ecology, 85, 1244-1250.

http://dx.doi.org/10.1890/03-0364

[5] Sagers, C.L., Ginger, S.M. and Evans, R.D. (2000) Carbon and nitrogen isotopes trace nutrient exchange in an ant-plant mutualism. Oecologia, 123, 582-586.

http://dx.doi.org/10.1007/PL00008863

[6] Coley, P.D., Lokvam, J., Rudolph, K., Bromberg, K., Sackett, T.E., Wright, L., Brenes-Arguedas, T., Dvorett, D., Ring, S., Clark, A., Baptiste, C., Pennington, T. and Kursar, T.A. (2005) Divergent defensive strategies of young leaves in two species of Inga. Ecology, 86, 2633-2643. http://dx.doi.org/10.1890/04-1283

[7] Heil, M., Rattke, J. and Boland, W. (2005) Postsecretory hydrolysis of nectar sucrose and specialization in ant/ plant mutualism. Science, 308, 560-563. http://dx.doi.org/10.1126/science.1107536

[8] Heil, M., Baumann, B., Krüger, R. and Linsenmair, K.E. (2004) Main nutrient compounds in food bodies of Mexican Acacia ant-plants. Chemoecology, 14, 45-52. http://dx.doi.org/10.1007/s00049-003-0257-x

[9] Michelangeli, F.A. (2003) Ant protection against herbivory in three species of Tococa (Melastomataceae) occupying different environments. Biotropica, 35, 181-188. http://dx.doi.org/10.1646/01509

[10] Thunberg, C.P. (1800) Prodromus plantarum Capensium: quas in promontorio Bonæ Spei Africes. Upsaliæ: J. Edman, Cape Town.

[11] National Research Council (U.S.) Advisory Committee on Technology Innovation (1979) Tropical legumes: Resources for the future: Report of an ad hoc panel of the Advisory Committee on Technology Innovation, Board on Science and Technology for International Development, Commission on International Relations, National Research Council. National Academies, Washington, 258.

[12] Sherbrooke, W.C. and Scheerens, J.C. (1979) Ant-visited extrafloral (calyx and foliar) nectaries and nectar sugars of Erythrina flabelliformis Kearney in Arizona. Annals of the Missouri Botanical Garden, 66, 472-481. http://dx.doi.org/10.2307/2398839

[13] Baker, H.G. (1975) Sugar concentrations in nectars from hummingbird flowers. Biotropica, 7, 37-41. http://dx.doi.org/10.2307/2989798

[14] Vitali-Veiga, M.J. and Machado, V.L.L. (2000) Flowering visitors of Erythrina speciosa Andr., Leguminosae. Revista Brasileira de Zoologia, 17, 369-383. http://dx.doi.org/10.1590/S0101-81752000000200007.

[15] Rico-Gray, V. and Oliveira, P.S. (2007) The ecology and evolution of ant-plant interactions. University of Chicago Press, Chicago.

[16] Bory, G. and, Clair-Maczulajtys, D. (1986) Composition of nectar and role of extrafloral nectars in Ailanthus glandulosa. Canadian Journal of Botany, 64, 247-253.

[17] Bory, G. and Clair-Maczulajtys, D. (1990) Importance of foliar nectaries in the physiology of tree of heaven Ailanthus glandulosa Desf. Simaroubaceae. Bulletin de la Societe Botanique de France Lettres Botaniques, 137, 139156.

[18] Becerra, J.X. and Venable, D.L. (1989) Extrafloral nectaries: A defense against ant-Homoptera mutualisms? Oikos, 55, 276-280. http://dx.doi.org/10.2307/3565432

[19] Kerner, A. (1878) Flowers and their unbidden guests. C. Kegan Paul \& Co., London.

[20] Wagner, D. and Kay, A. (2002) Do extrafloral nectaries distract ants from visiting flowers? An experimental test of an overlooked hypothesis. Evolutionary Ecology Research, 4, 293-305.

[21] Boucher, D.H. (1988) The biology of mutualism: Ecology and evolution. Oxford University Press, New York.

[22] Shannon, C.E. (1948) A mathematical theory of communication. The Bell System Technical Journal, 27, 379-423.

[23] Bluthgen, N., Gottsberger, G. and Fiedler, K. (2004) Sugar and amino acid composition of ant-attended nectar and honeydew sources from an Australian rainforest. Austral Ecology, 29, 418-429. http://dx.doi.org/10.1111/j.1442-9993.2004.01380.x

[24] Del Claro, K. and Oliveira, P.S. (1993) Ant-homoptera interaction: Do alternative sugar sources distract tending ants? Oikos, 68, 202-206. http://dx.doi.org/10.2307/3544831

[25] van Wyk, B.E. (1993) Nectar sugar composition in southern African Papilionoideae (Fabaceae). Biochemical Systematics and Ecology, 21, 271-277. http://dx.doi.org/10.1016/0305-1978(93)90045-S 
[26] Southwood, T.R.E., Moran, V.C. and Kennedy, C.E.J. (1982) The richness, abundance and biomass of the arthropod communities on trees. The Journal of Animal Ecology, 51, 635-649. http://dx.doi.org/10.2307/3988

[27] Bronstein, J.L. (1994) Conditional outcomes in mutualistic interactions. Trends in Ecology \& Evolution, 9, 214217. http://dx.doi.org/10.1016/0169-5347(94)90246-1
[28] Janzen, D.H. (1973) Dissolution of mutualism between Cecropia and its Azteca ants. Biotropica, 5, 15-28. http://dx.doi.org/10.2307/2989677

[29] Putz, F. and Holbrook, N. (1988) Further observations on the dissolution of mutualism between Cecropia and its ants: the Malaysian case. Oikos, 53, 121-125. http://dx.doi.org/10.2307/3565671. 